\title{
Psychological Rebuilding as a Coping Strategy for Post COVID-19 Mental Health Problems in Nigeria
}

\author{
Dr. Olayinka M. AYANNUGA \\ Department of Educational Psychology, \\ Federal College of Education (Technical), \\ Akoka, Lagos State, Nigeria
}

\begin{abstract}
Coronavirus Disease 2019 (COVID-19) is an ongoing pandemic and major health crisis going on in the world currently. This global challenge is increasing mental health issues among the general population. There is no doubt the mental health of the average Nigerian has been negatively impacted due to worry, stress, sadness, anxiety, depression over coronavirus and needed to be addressed urgently. COVID-19's distribution along Nigeria's geopolitical zones with confirmed, active, discharged and death cases were discussed. This paper stresses on bringing succor to assist people to return to the good situation that they were in before existence of COVID-19 crisis through psychological rebuilding strategies. Counsellors and psychologists need to prevent both the development and complications through different online therapy, Cognitive Behaviour Therapy and ways to reduce stigma of mental health problems in affected persons were considered. It concludes by reemphasizing that there is no doubt the pandemic period is a very difficult time that comes with a lot of challenges like mental health problems which can almost be impossible for an individual to manage and get out of it by oneself, psychological rebuilding therefore is necessary to put people back on their feet now and after the crisis. A lot of recommendations were made to reduce post covid-19 mental health problems.
\end{abstract}

Key words: Coping Strategy; COVID-19; Mental Health; Psychological Rebuilding

\section{Introduction}

Coronavirus Disease 2019 (COVID-19) is a global disease taking the form of a pandemic, it has affected millions of people over the past few months while many are already dead and there is still daily increase in its mortality rate. COVID-19 pandemic is turning out to be a major stressor for most of humanity because such an event has not affected people across the globe in a long time. Traumatic events like COVID-19 are 


\section{$2^{\text {nd }}$ International Conference on Modern Research in EDUCATION, TEACHING AND LEARNING}

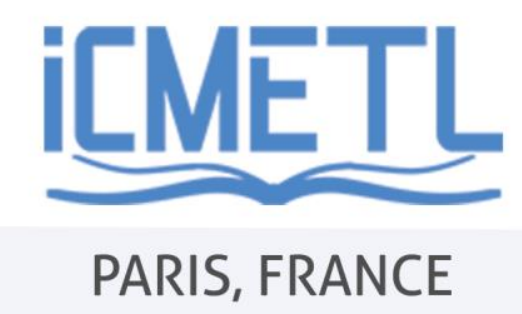

20-22 NOVEMBER, 2020

not easy for anyone to comprehend or accept, people are confined to their homes during a pandemic like this and this can have negative health outcomes. It comes with experience of distressing thoughts, feelings, and physical symptoms, it is unprecedented and is impacting on society and the world in lots of different ways. Studies in Post-Severe Acute Respiratory Syndrome (Post-SARS) pandemic or postEbola indicate that even after recovering physically from the disease, individuals suffered from social and psychological problems and similar could be the impact with this pandemic (Bobdey and Ray, 2020). Evidence suggests that vulnerable groups who are confined to their homes during any pandemic can have negative health outcomes.

People become physically less active and have much irregular sleep patterns, less favourable diets and many more abnormal lives, resulting in weight gain and a loss of cardiorespiratory fitness during and even after the pandemic. Also, there are other direct and indirect implications of the closure of offices, cinema house, gym, which are particularly large in healthcare occupations (Bayham and Fenichel, 2020). The stocks and flow of physical and financial assets are interrupted during this crisis period. An increase in health budget and a lowering of overall GDP is sure to impact the whole world (McKibbin and Fernando, 2020).

The mental health of the average Nigerian has been negatively impacted due to worry and stress over coronavirus. As the pandemic wears on, it is likely the mental health problem will increase as measures taken to slow the spread of the virus, such as social distancing, wearing a nose mask, business and school closures, and shelter-in-place orders, lead to greater isolation and potential financial distress even after the pandemic (McKibbin and Fernando, 2020). Stigma, fear and anxiety are other aspects of the outbreak of a pandemic. It can present major barriers against healthcare seeking, social marginalization, distrust in health authorities and distortion of public perceptions of risk, resulting in mass panic among citizens and the disproportionate allocation of healthcare resources by politicians and health professionals (Barrett and Brown, 2008).

\section{Nigeria COVID-19 Case}

The COVID-19 pandemic in Nigeria is part of the worldwide pandemic of Coronavirus Disease 2019 (COVID-19) caused by Severe Acute Respiratory Syndrome Corona Virus 2 (SARS-CoV-2). The first confirmed case in Nigeria was announced on 27 February 2020, when an Italian citizen in Lagos tested positive for the virus. As at 12 noon of $11^{\text {th }}$ July, 2020 Nigeria record 175,656 Samples Tested out of which 31,323 were confirmed cases, 12,795 Discharged Cases, 17,819 still Active Cases while the 
number of deaths is 709. Tables below shows the geopolitical zones distribution of coronavirus cases in Nigeria.

Table 1: Coronavirus cases in North Central States of Nigeria

\begin{tabular}{|l|l|l|l|l|}
\hline \multicolumn{1}{|c|}{ States } & Confirmed Cases & Active Cases & Discharged Cases & Deaths \\
\hline Benue & 121 & 80 & 35 & 6 \\
\hline FCT & 2,433 & 1,665 & 733 & 35 \\
\hline Kogi & 5 & 0 & 3 & 2 \\
\hline Kwara & 311 & 131 & 168 & 12 \\
\hline Nasarawa & 238 & 117 & 113 & 8 \\
\hline Niger & 135 & 20 & 108 & 7 \\
\hline Plateau & 499 & 241 & 242 & 16 \\
\hline Total & $\mathbf{3 , 7 4 2}$ & $\mathbf{2 , 2 5 6}$ & $\mathbf{1 , 4 0 2}$ & $\mathbf{8 6}$ \\
\hline
\end{tabular}

Table 2: Coronavirus cases in North East States of Nigeria

\begin{tabular}{|l|l|l|l|l|}
\hline \multicolumn{1}{|c|}{ States } & Confirmed Cases & Active Cases & Discharged Cases & Deaths \\
\hline Adamawa & 100 & 22 & 71 & 7 \\
\hline Bauchi & 519 & 8 & 498 & 13 \\
\hline Borno & 586 & 96 & 455 & 35 \\
\hline Gombe & 527 & 119 & 387 & 21 \\
\hline Taraba & 27 & 16 & 11 & 0 \\
\hline Yobe & 62 & 3 & 51 & 8 \\
\hline Total & $\mathbf{1 , 8 2 1}$ & $\mathbf{2 6 4}$ & $\mathbf{1 , 4 7 3}$ & $\mathbf{8 4}$ \\
\hline
\end{tabular}

Table 3: Coronavirus cases in North West States of Nigeria

\begin{tabular}{|l|l|l|l|l|}
\hline \multicolumn{1}{|c|}{ States } & Confirmed Cases & Active Cases & Discharged Cases & Deaths \\
\hline Kaduna & 946 & 312 & 622 & 12 \\
\hline Katsina & 655 & 191 & 441 & 23 \\
\hline Kano & 1,303 & 221 & 1,030 & 52 \\
\hline Kebbi & 86 & 16 & 63 & 7 \\
\hline Sokoto & 153 & 2 & 135 & 16 \\
\hline Jigawa & 321 & 2 & 308 & 11 \\
\hline Zamfara & 76 & 0 & 71 & 5 \\
\hline Total & $\mathbf{3 , 5 4 0}$ & $\mathbf{7 4 4}$ & $\mathbf{2 , 6 7 0}$ & $\mathbf{1 2 6}$ \\
\hline
\end{tabular}

Table 4: Coronavirus cases in South East States of Nigeria

\begin{tabular}{|l|l|l|l|l|}
\hline \multicolumn{1}{|c|}{ States } & Confirmed Cases & Active Cases & Discharged Cases & Deaths \\
\hline Abia & 402 & 134 & 265 & 3 \\
\hline Anambra & 93 & 19 & 65 & 9 \\
\hline Ebonyi & 508 & 5 & 497 & 6 \\
\hline Enugu & 469 & 192 & 263 & 14 \\
\hline Imo & 359 & 290 & 61 & 8 \\
\hline Total & $\mathbf{1 , 8 3 1}$ & $\mathbf{6 4 0}$ & $\mathbf{1 , 1 5 1}$ & $\mathbf{4 0}$ \\
\hline
\end{tabular}

Table 5: Coronavirus cases in South South States of Nigeria

\begin{tabular}{|l|l|l|l|l|}
\hline \multicolumn{1}{|c|}{ States } & $\begin{array}{c}\text { Confirmed } \\
\text { Cases }\end{array}$ & Active Cases & $\begin{array}{c}\text { Discharged } \\
\text { Cases }\end{array}$ & \multicolumn{1}{c|}{ Deaths } \\
\hline Akwa Ibom & 134 & 60 & 71 & 3 \\
\hline Bayelsa & 299 & 128 & 153 & 18 \\
\hline
\end{tabular}




\begin{tabular}{|l|l|l|l|l|}
\hline Cross River & 5 & 1 & 3 & 1 \\
\hline Delta & 1,348 & 863 & 454 & 31 \\
\hline Edo & 1,593 & 607 & 929 & 57 \\
\hline Rivers & 1,343 & 450 & 847 & 46 \\
\hline Total & $\mathbf{4 , 7 2 2}$ & $\mathbf{2 , 1 9 0}$ & $\mathbf{2 , 4 5 7}$ & $\mathbf{1 5 6}$ \\
\hline
\end{tabular}

Table 6: Coronavirus cases in South West States of Nigeria

\begin{tabular}{|l|l|l|l|l|}
\hline \multicolumn{1}{|c|}{ States } & $\begin{array}{c}\text { Confirmed } \\
\text { Cases }\end{array}$ & Active Cases & $\begin{array}{c}\text { Discharged } \\
\text { Cases }\end{array}$ & Deaths \\
\hline Lagos & 12,051 & 10,140 & 1,764 & 147 \\
\hline Oyo & 1,689 & 745 & 925 & 19 \\
\hline Ogun & 1,063 & 336 & 705 & 22 \\
\hline Ondo & 606 & 462 & 124 & 20 \\
\hline Osun & 212 & 121 & 84 & 7 \\
\hline Ekiti & 46 & 4 & 40 & 2 \\
\hline Total & $\mathbf{1 5 , 6 6 7}$ & $\mathbf{1 1 , 8 0 8}$ & $\mathbf{3 , 6 4 2}$ & $\mathbf{2 1 7}$ \\
\hline
\end{tabular}

Table 7: Nigeria COVID-19 Geopolitical Zones Distribution

\begin{tabular}{|l|l|l|l|l|}
\hline $\begin{array}{c}\text { Geopolitical } \\
\text { Zones }\end{array}$ & $\begin{array}{c}\text { Confirmed } \\
\text { Cases }\end{array}$ & $\begin{array}{c}\text { Active } \\
\text { Cases }\end{array}$ & $\begin{array}{c}\text { Discharged } \\
\text { Cases }\end{array}$ & Deaths \\
\hline North Central & 3,742 & 2,256 & 1,402 & 86 \\
\hline North East & 1,821 & 264 & 1,473 & 84 \\
\hline North West & 3,540 & 744 & 2,670 & 126 \\
\hline South East & 1,831 & 640 & 1,151 & 40 \\
\hline South South & 4,722 & 2,190 & 2,457 & 156 \\
\hline South West & 15,667 & 11,808 & 3,642 & 217 \\
\hline Total & $\mathbf{3 1 , 3 2 3}$ & $\mathbf{1 7 , 9 0 2}$ & $\mathbf{1 2 , 7 9 5}$ & $\mathbf{7 0 9}$ \\
\hline
\end{tabular}

\section{NIGERIA COVID-19 GEOPOLITICAL ZONES DISTRIBUTION}

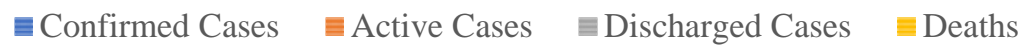

\begin{tabular}{|c|c|c|c|c|c|c|c|}
\hline $\begin{array}{r}35,000 \\
30,000 \\
25,000 \\
20,000 \\
15,000 \\
10,000 \\
5,000\end{array}$ & 트르- & & 트_E & & 틀=辰 & 韭聖旦 & \\
\hline & $\begin{array}{l}\text { North } \\
\text { Central }\end{array}$ & $\begin{array}{c}\text { North } \\
\text { East }\end{array}$ & $\begin{array}{l}\text { North } \\
\text { West }\end{array}$ & $\begin{array}{c}\text { South } \\
\text { East }\end{array}$ & $\begin{array}{l}\text { South } \\
\text { South }\end{array}$ & $\begin{array}{l}\text { South } \\
\text { West }\end{array}$ & Total \\
\hline 玉 Confirmed Cases & 3,742 & 1,821 & 3,540 & 1,831 & 4,722 & 15,667 & 31,323 \\
\hline E Active Cases & 2,256 & 264 & 744 & 640 & 2,190 & 11,808 & 17,902 \\
\hline E Discharged Cases & 1,402 & 1,473 & 2,670 & 1,151 & 2,457 & 3,642 & 12,795 \\
\hline Deaths & 86 & 84 & 126 & 40 & 156 & 217 & 709 \\
\hline
\end{tabular}




\section{$2^{\text {nd }}$ International Conference on Modern Research in EDUCATION, TEACHING AND LEARNING}

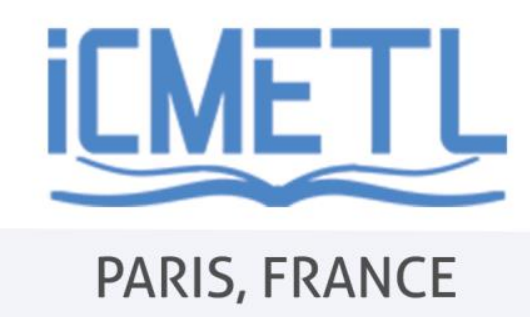

20-22 NOVEMBER, 2020

Above chart presents at a glance the Nigeria covid-19 geopolitical zones distribution as at 12 noon of $11^{\text {th }}$ July, 2020

\section{Psychological Rebuilding}

Concern and worry are normal and adaptive during a pandemic. Many of us are concerned about our health and that of our loved ones, especially those of us with older and possibly vulnerable family and friends. It is understandable to be concerned about our jobs and financial situation, particularly if the current outbreak continues for weeks or months (ABCT, 2020). Psychological rebuilding connotes that psychologist needs to assists people to return to the good situation that they were in before the existence of unpleasant event COVID-19. It also includes the daily guidance and support for dealing with their stress and other mental health issues. Part of their goals should be to prevent psychological deterioration using evidence-based strategies for stress management and to foster a safe community to increase social support and improve their mental health. Among issues to be covered are resilience and characteristics of resilient people, such as building social support, focusing on positive emotions and finding meaning in the experience.

Psychologists can assist citizen to understand how these illnesses affect them, how it can be prevented and/or effectively treated is mandatory. It is also essential that psychological crisis intervention should be part of the public health response to the COVID-19 outbreak for prevention and control mechanism at all levels, using science to enhance health and well-being and that the interventions should be differentiated by groups. According to Dong \& Bouey (2020) the intervention workforce comprises psychological outreach teams led by psychiatrists and mental health professionals and psychological support hotline teams.

Again, part of psychological rebuilding is that therapists give treatment/management that is likely to alleviate or prevent a deterioration of the mental health disorder. Psychological impacts of COVID-19 are much, and its impacts can be particularly difficult for vulnerable people who may be experiencing cognitive decline. People are likely to be experiencing worry, anxiety and fear, and this can include such as a fear of dying, a fear of their relatives dying, financial constraint and even where to start from or how to continue life after the pandemic. This is a big challenge for this professional as it will be time consuming, rethinking, reengineering and learning new ways of handling different and many mental health problems that come with the crisis. 


\section{$2^{\text {nd }}$ International Conference on Modern Research in EDUCATION, TEACHING AND LEARNING}

\section{CCMETL \\ PARIS, FRANCE}

20-22 NOVEMBER, 2020

\section{COVID-19 and Mental Health Problems}

Mental health problems, mental illness and mental disorder are used interchangeably. It significantly affects how a person feels, thinks, behaves, and interacts with other people. Mental health problems are a growing public health concern. Mental health is a key part of our successful life and our overall well-being. The World Health Organization (WHO, 2013) states that there is no health without mental health. Our capacity to function well is depending on our mental health. It is the source of our collective and individual ability as people to reach our full potential in life. Mental health problems are more common and include the mental ill health that can be experienced temporarily as a reaction to the stresses of everyday life.

The human emotional response to disasters like COVID-19 is relatively predictable, many people will experience the unprecedented impact of the COVID-19 outbreak on their mental health at the end of the crisis. As the COVID-19 pandemic has been spreading rapidly across the globe, the foremost mental health issue has raised the level of stress or anxiety expressed in public mental health term (Dong \& Bouey 2020). Also, according to Nirmita, Rabah, Kendal, Cynthia, Rachel, Liz, Cailey, and Priya (2020) during this unprecedented time of uncertainty and fear, it is likely that mental health issues and substance use disorders among people with these conditions will be exacerbated.

The mental health and wellbeing of whole societies have been severely impacted by the COVID-19 pandemic and needed to be addressed urgently. Some people may due to Covid-19 may be experiencing loneliness which can worsen mental health, the harsh versions of 'normal' emotions, such as stress, sadness and anxiety, depression, obsessive-compulsive disorder (OCD), phobias, post-traumatic stress disorder (PTSD), panic disorders, suicide thoughts, feeling of anger and so on would have affected a couple of people.

\subsection{Mental Health Counselling and Post Covid-19}

Although counsellors/psychologist and therapists will not be exempted from challenges of COVID-19 and knock- on effects. This challenge will open new ways of moving forward in their profession by responding to individual and societal needs. Mental Health Counselling can be understood as "an aggregate of the specific educational, scientific, and professional contributions of the disciplines of education, psychology, and counselling" (Spruill \& Fong, 1990). Mental health counsellors are concerned with health and with the wide variety of circumstances, socially and individually, that can impair or inhibit the functioning of a person's life. Mental health counselling is 


\section{$2^{\text {nd }}$ International Conference on Modern Research in EDUCATION, TEACHING AND LEARNING}

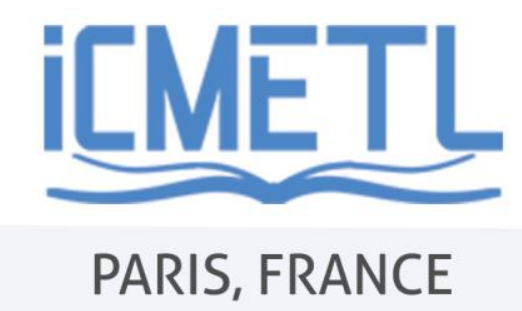

20-22 NOVEMBER, 2020

designed to contribute to the vitality, vigor and to the soundness in body, mind, spirit, as well as social connection that sustains well-being, and so is considered, by our society, to be health.

A mental illness is not different, it is not an illness for which anyone should be blamed and it is not easily possible for someone with a mental illness to make the symptoms go away just by strength of will or self. People with a mental illness need the understanding and support given to people with a physical illness by doctor and psychologists. Therefore, to reduce the health, social and economic burdens of mental disorders after COVID-19, it is essential that all stakeholders including counsellors pay attention to patients that show symptoms.

It is undisputed that the current COVID-19 emergency will have long lasting consequences and effects on the mental health of all people, affecting the general population with astonishingly heightened stress. Since it is rarely possible for someone with a mental illness to make the symptoms go away just by strength of will people with a mental illness need the same understanding and support given to people with a physical illness by professionals like a counsellor and psychologist.

\subsection{Accessing Online Therapy as Psychological Rebuilding Strategy}

COVID-19 crisis does not have to be an inhibitor of innovation, but can be an invitation for innovation. Treatments of mental health problems mainly are not drugs it includes cognitive and behavioural psychological therapies, psychosocial support, psychiatric disability rehabilitation, avoidance of risk factors such as harmful alcohol and other drug use, and learning self-management skills. Mental health promotion and other methods are needed. Mental health promotion often refers to positive mental health, it aims to impact on determinants of mental health so as to increase positive mental health, to reduce inequalities, to build social capital, to create health gain and to narrow the gap in health expectancy between countries and groups (Jakarta Declaration for Health Promotion, WHO, 1997). Mental health promotion interventions vary in scope and include strategies to promote the mental wellbeing of those who are not at risk, those who are at increased risk, and those who are suffering or recovering from mental health problems so it is all encompassing.

The 'new normal' of lockdown due to the COVID-19 pandemic has forced counsellors and psychologists to adapt their practice (Liesbeth, 2020). Online therapy can be a powerful tool for mental health, especially during and after such a stressful time like COVID-19 crisis. Online therapy is not new; e-therapy started in the 1990s as the Internet became increasingly common. There is a wealth of evidence for the power and 


\section{$2^{\text {nd }}$ International Conference on Modern Research in EDUCATION, TEACHING AND LEARNING}

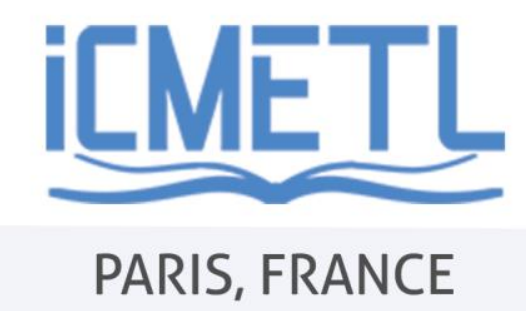

20-22 NOVEMBER, 2020

potential of this medium in delivering therapies for mental health disorders. They include steps that individuals can take for themselves and their families to reduce negative effects and improve their ability to function well as normal individuals.

As recommended by Ho, Chee, \& Ho (2020) in this era of technology, healthcare services can be introduce by providing online psychological support services for those individuals who lost their close relatives, jobs, wealth, those who were forced to relocate or stay with their children at home and so on due to COVID-19. According to a report in China January 2020, it was indicated that, for many developing countries, telemedicine should be considered, given the widespread adoption of smartphones, to help remove barriers to accessing quality care for mental health. (National Health Commission of China, 2020).

This pandemic more than ever, should make the counsellors be able to access online mental health therapy more than before. Also, the fact that lots of people are now unwilling or unable to access face-to-face therapy, due to their health and ongoing Government restrictions, which means that online support is currently the preferred route for many. Speaking to a therapist online can feel strange, at least at first. However, by treating your online therapy sessions like usual and because online therapy is accessible in a different way, there are unique things you can do to integrate it into your client's daily life for better performance.

The internet has interconnected much of the world, which is why we're able to benefit from online mental health therapy. Sending messages and emails can help to keep you connected to your clients even if you can't see them in person. You can also go one step further and use video call platforms or zoom so you can physically see someone as you talk to them. Counsellors can commit to only spending time online for helpful reasons such as accessing therapy, doing online exercise, or keeping in touch with your clients and loved ones. Therapists might also be involved in giving media interviews, posting online or partnering with public officials to deliver messages about wellness and resilience for survivors of COVID-19 and others who has been brutalized mentally. Psychologists may recommend mindfulness tools or smartphone applications in other to reach out to people. Doing this will help counsellors greatly, you'll be able to safeguard your wellbeing and that of others during such a difficult time.

\subsection{Tips on Online Therapy During the COVID-19 Outbreak}

Online Therapy is possible during the COVID-19 outbreak according to Finch (2020). Points explained below will help in online therapy for counsellors during and post COVID-19 for therapists. 


\section{$2^{\text {nd }}$ International Conference on Modern Research in EDUCATION, TEACHING AND LEARNING}

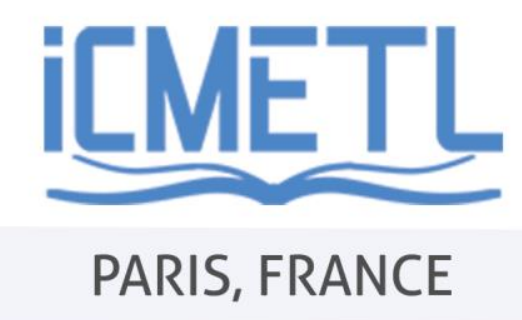

20-22 NOVEMBER, 2020

i. Choose a safe space and intentional time for therapy: One of the most touted benefits of online therapy is the fact that you can do it anytime, anywhere. You don't have to be in your or office neither does it have to be during working hour. You can choose any other convenient time.

ii. Expect some awkwardness at first: No matter what platform you are using as a therapist and how tech-savvy they are, it's still going to be a different experience from in-person — so don't be alarmed if it doesn't feel like you and your client are "in-sync" right away.

iii. Be flexible with the format of your therapy: Some therapy platforms use a combination of messaging, audio, and video, while others are a typical session over webcam. If you have options, it's worth exploring what combination of text, audio, and video works best for you. One of the benefits of teletherapy is that you have a lot of different tools at your disposal. Be open to experimenting! Don't be rigid to a particular platform.

iv. Lean into the unique parts of telemedicine: There are some things you can do with online therapy that you can't necessarily do in-person by getting creative. New innovation and creativity with how you use the tools available to you can make online therapy feel a lot more engaging.

v. In the absence of bodily cues, practice naming your emotions more explicitly: Therapists' ability to read clients especially their non-verbal behaviour is something that might be taken for granted as we pivot to telemedicine. This is why it can be really beneficial to practice naming our emotions and reactions more explicitly. These are useful skills in self-awareness regardless, but online therapy is a great excuse to start flexing those muscles in a safe environment.

vi. Be willing to name what you need - even if it seems 'silly': With COVID-19 in particular, an active pandemic means that many people if not everybody are struggling with getting some of our most fundamental human needs met. Taking care of ourselves is going to be a fundamental challenge at times. It can be tempting to invalidate our responses to COVID-19 as being an "overreaction," which can make us reluctant to disclose or ask for help.

vii. Don't be afraid to give your therapist feedback: A lot of therapists who are making the shift to telemedicine are relatively new to it, which means there will almost certainly be hiccups along the way. Online therapy itself is a more recent development in the field, and not all clinicians have proper training on how to translate their in-person work to a digital platform. As you both (clients and therapist) experiment with online therapy, feedback is essential to figuring out 


\section{$2^{\text {nd }}$ International Conference on Modern Research in EDUCATION, TEACHING AND LEARNING}

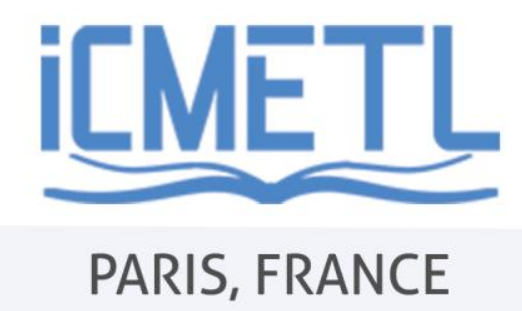

20-22 NOVEMBER, 2020

what does and doesn't work for you. Keep communication open and transparent with your client. It is called evaluation in counselling and it is important.

\subsection{Cognitive Behaviour Therapy as Psychological Rebuilding Strategy}

Cognitive Behaviour Therapy (CBT) is a type of evidence-based treatment to reduce distress and unpleasant psychological symptoms. It is based on the idea that what we do is rooted in our thoughts, our feelings and our behaviors and that by changing them, we can improve our mood and wellbeing. CBT is a special type of talk-therapy provided by a trained mental health professional that is structured and time-limited, usually occurring for around 12-20 sessions. CBT is the most rigorously researched type of psychotherapy, and studies have shown that it tends to work better and faster than other types of talk therapy to address a variety of psychological concerns. Counsellors can use CBT to reduce our fears, conquer overwhelmed feelings, change our thinking and act in meaningful ways. A variety of CBT approaches for specific populations have been found to be effective in reducing symptoms associated with depression, anxiety, post-traumatic stress, panic attacks, social anxiety, disordered eating, insomnia, headaches, psychosis, pain and more.

According to British Association of Behavioral \& Cognitive Therapies (2020) tips from CBT to help manage anxiety related to Coronavirus are:

i. It's normal to feel all sorts of feelings in response to the pandemic, including fear, sadness, anger, to feel 'cut off', or to feel a mix of these things.

ii. Our body's 'fight or flight' response is a physical reaction that can be very physical, including feeling short of breath, having a racing heart, or feeling hot.

iii. There is a huge amount of information about coronavirus, some of it from more reputable sources than others. Continually checking the news can make us feel more anxious. Consider limiting how often you look and making sure you get the news from reliable sources.

iv. Avoid checking repeatedly for symptoms of illness - it can accidentally make you feel worse.

v. Keep breathing - taking a moment to breathe slowly and ground yourself into your seat and feet can be helpful.

vi. Stay connected with people - we can't spend time physically but we can call, write, email and stay in touch with loved ones.

vii. Seek help if you need it, especially if you have a pre-existing anxiety condition. Lots of therapists are offering remote consultations now. 


\section{ICMETL \\ PARIS, FRANCE}

\section{0-22 NOVEMBER, 2020}

\section{How Counsellors can Reduce Stigma of Mental Health Problems}

i. Talk about mental illness openly with everyone online - it is surprising how many people are affected by mental illness, particularly the highly prevalent disorders of depression and anxiety during COVID-19 crisis.

ii. Reorienting and reeducating the community to overcome negative stereotypes based on misconceptions of COVID-19 is essential through social media.

iii. Support the development of resilience: learn ways to deal with stress in relationships, situations, and events.

iv. Assist friends and family with a mental illness to obtain care and treatment as early as possible before it escalates. Counsellors can help get in touch with NCDC via phone call for prompt assistance

v. Counsellors can use their professional skills to ensure that quality support and treatment services are provided to people with mental illness to promote recovery.

vi. Actively support the families and cares of people who have mental illness, who also experience the confusion, distress, and stigma that can accompany mental illness.

vii. Counsellors should address discrimination in every area of life, including community, employment, education, and the provision of goods, services, and facilities to affected persons.

\section{Conclusion}

There is no doubt the pandemic period is a very difficult time because it comes with a lot of challenges like mental health problems which can have serious, even fatal, consequences on the affected people. Since it is almost impossible for an individual to manage this mental health illness and get out of it by oneself, psychological rebuilding is necessary to put people back on their feet now and after the crisis. This can greatly be achieved with the help of the psychologist/counsellors. Different online strategies are considered to be effective for this great assignment ahead. Again, online Cognitive Behavioral Therapy was considered to also be helpful with managing anxiety, fear, low mood and other related problems because there are lots of well-researched principles of CBT to confirm this. 


\section{Recommendations}

i. Everyone across the globe should see this period as a challenging period therefore be ready to do all that could be done to come out of it triumphantly.

ii. Orientation and propagation of psychological rebuilding is essential for the citizenry during and after the pandemic.

iii. Counsellors/psychologist needs a lot of training and retraining programs for effectiveness in this period of pandemic and after it.

iv. Financial assistance is needed from government and NGOs for proper planning and execution on this psychological rebuilding.

v. The government should prepare and train mental health staff in the management of emergency like outbreak of disease and especially preventive measure.

\section{References}

Association for Behavioral and Cognitive Therapies (ABCT, 2020) 54 ${ }^{\text {th }}$ Annual Convention.

Barrett R, Brown P. J. (2008) Stigma in the time of influenza: social and institutional responses to pandemic emergencies. J Infect Dis 197(Suppl 1): S34-S37

Bayham J, \& Fenichel E. P. (2020) The impact of school closure for COVID-19 on the US Healthcare Workforce and the Net Mortality Effects. medRxiv. 2020.03.09.20033415

Bobdey S. \& Ray S (2020) Going viral-Covid-19 impact assessment: a perspective beyond clinical practice. J Mar Med Soc 22(1):9

Dong, L., \& Bouey, J. (2020). Public Mental Health Crisis during COVID-19 Pandemic, China. Emerging Infectious Diseases, 26(7), 1616-1618. https://dx.doi.org/10.3201/eid2607.200407.

Finch Sam Dylan (2020). Tips for Making the Most of Online Therapy During the COVID-19 Outbreak healthline

Ho C. S., Chee C. Y., \& Ho R. C. (2020) Mental health strategies to combat the psychological impact of COVID-19 beyond paranoia and panic. Ann Acad Med Singap 49(1): 1

Jakarta Declaration on Leading Health Promotion into the 21st Century (1997). The Fourth International Conference on Health Promotion: New Players for a New Era - Leading Health Promotion into the 21st Century, Jakarta, Indonesia, 2125 July 1997 
Liesbeth (2020). Guidance for online therapy during COVID-19. https://www.nationalelfservice.net/treatment/digital-health/online-therapyduring-covid-19/ Cited 29 June 2020

McKibbin W. J. \& Fernando R. (2020) The global macroeconomic impacts of COVID19: seven scenarios. Social Science Research Network, Rochester, NY. Report No.: ID 3547729. https://papers.ssrn.com/abstract $1 / 43547729$. Cited 29 June 2020

National Health Commission of China (2020). Principles of the emergency psychological crisis interventions for the new coronavirus pneumonia. Cited 2nd July 2020 on http://www.nhc.gov.cn/jkj/s3577/202001/6adc08b966594253b2b791be5c3b94 67External Link

Nirmita Panchal, Rabah Kamal, Kendal Orgera, Cynthia Cox, Rachel Garfield, Liz Hamel, Cailey Muñana, and Priya Chidambaram. (2020). The Implications of COVID-19 for Mental Health and Substance Use - Issue Brief - 9440. Retrieved from https://www.kff.org/coronavirus-covid-19/issue-brief/theimplications-of-covid-19-for-mental-health-and-substance-use/ on $29^{\text {th }}$ June 2020

Spruill, D. A., \& Fong, M. L. (1990). Defining the domain of mental health counseling: From identity confusion to consensus. Journal of Mental Health Counseling, 12(1), 12-23.

WHO (2013). Bulletin of the World Health Organization; 91:3-3A. doi: 10.2471/BLT.12.115063 